\title{
Mechanisms of vegetation uprooting by flow in alluvial non-cohesive sediment
}

\author{
K. Edmaier ${ }^{1,}$, P. Burlando ${ }^{1}$, and P. Perona ${ }^{1,{ }^{*}}$ \\ ${ }^{1}$ Institute for Environmental Engineering, ETHZ, Wolfgang-Pauli-Str. 15, 8093 Zurich, Switzerland \\ *now at: AHEAD, IIE, EPFL-ENAC, Station 2, Lausanne, Switzerland
}

Received: 30 November 2010 - Published in Hydrol. Earth Syst. Sci. Discuss.: 28 January 2011

Revised: 5 May 2011 - Accepted: 12 May 2011 - Published: 26 May 2011

\begin{abstract}
The establishment of riparian pioneer vegetation is of crucial importance within river restoration projects. After germination or vegetative reproduction on river bars juvenile plants are often exposed to mortality by uprooting caused by floods. At later stages of root development vegetation uprooting by flow is seen to occur as a consequence of a marked erosion gradually exposing the root system and accordingly reducing the mechanical anchoring. How time scales of flow-induced uprooting do depend on vegetation stages growing in alluvial non-cohesive sediment is currently an open question that we conceptually address in this work. After reviewing vegetation root issues in relation to morphodynamic processes, we then propose two modelling mechanisms (Type I and Type II), respectively concerning the uprooting time scales of early germinated and of mature vegetation. Type I is a purely flow-induced drag mechanism, which causes alone a nearly instantaneous uprooting when exceeding root resistance. Type II arises as a combination of substantial sediment erosion exposing the root system and resulting in a decreased anchoring resistance, eventually degenerating into a Type I mechanism. We support our conceptual models with some preliminary experimental data and discuss the importance of better understanding such mechanisms in order to formulate sounding mathematical models that are suitable to plan and to manage river restoration projects.
\end{abstract}

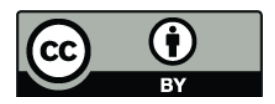

Correspondence to: $\mathrm{K}$. Edmaier (katharina.edmaier@epfl.ch)

\section{Introduction}

Riparian woodlands are of valuable ecological, biological and hydrological importance also according to several factors like aesthetics, biodiversity or recreation (Tanaka and Yagisawa, 2009; Mahoney and Rood, 1998) and thus for river restoration planning. Besides providing natural habitat for various river ecosystem species (Hughes, 1997), riparian trees interact with river streamflow thus contributing to a number of fundamental feedback dynamics. Examples are the lateral and longitudinal connectivity between the river and the floodplain, the control of water quality by biological filtering, the influence on sedimentary processes (Edwards et al., 1999; Schnauder and Moggridge, 2009) and the spatial spreading of species (Johnson, 2000; Mahoney and Rood, 1998). A key point of these dynamics concerns the temporary stabilization of the non-cohesive sediment as a result of root mechanical anchoring (Karrenberg et al., 2003), and how this affects the temporal and the spatial scales of morphodynamic processes (Perona et al., 2009b; Seminara, 2010).

Erosion of vegetated cohesive soil by flow is a well studied problem, with obvious engineering relevance as far as the stability of terrain slopes or river banks are concerned (e.g. Millar, 2000). On the contrary, erosion of vegetated non-cohesive alluvial sediment such that forming river bars and islands has only recently been attracting the interest of scientific communities with regard to river restoration projects (e.g. Palmer et al., 2007) and the related implications for the connected riparian ecosystem (Decamps et al., 1988; Hughes, 1997; Tockner and Stanford, 2002).

The propagation of vegetation in alluvial sediment along river beds is driven by either germination of seedlings (Moggridge and Gurnell, 2010) or vegetative reproduction of

Published by Copernicus Publications on behalf of the European Geosciences Union. 
Large Woody Debris (LWD) (Edwards et al., 1999; Mahoney and Rood, 1998). Although reproduction is usually quite high, only few individuals of riparian pioneer vegetation succeed in becoming mature trees or shrubs due to high mortality for young vegetation by various factors like floods, droughts, ice or grazing (Johnson, 2000; Mahoney and Rood, 1998). Flooding can cause mortality either by plants uprooting (Tanaka and Yagisawa, 2009) or by substantial deposition of sediment that buries the (young) plants underneath (Johnson, 2000). Particularly, mortality caused by flow-induced uprooting hinders many interesting, yet not well understood aspects related to the complex flow in canopies hydrodynamics and emerging as combination of different processes and factors.

In this work we will focus on the mortality of riparian vegetation caused by flow-induced uprooting in alluvial sediment. We conjecture non-cohesive alluvial soil to offer a unique possibility to study the nature of erosion process in vegetated sediments as a function of roots development, under the hypothesis that additional soil cohesion is caused by root anchoring only. We then formulate two conceptual models that are useful to understand the different time scales of vegetation uprooting in relation to root development and its statistical distribution on alluvial forms. Next Section offers a state-of-the-art review of vegetation roots related issues that are useful to quantify our research questions. Then, in Sect. 3 we propose and discuss the conceptual models of uprooting Type I and II, supported by preliminary experimental observations (Sect. 4). In Sect. 5 we discuss the relevance of our work in the context of river restoration and conclude the work.

\section{Vegetation roots issues and morphodynamic processes: a state-of-the-art review}

\subsection{Root architecture description and modelling}

Morphological and functional aspects of plant roots are well documented (e.g., Cannon, 1949; Gregory et al., 1987; Jackson et al., 1996; Fitter, 2002) and also mathematically described (Berntson and Stoll, 1997; Berntson, 1997; Bouma et al., 2001; Sakai, 2001). Attempts at classifying root families can already be found in the pioneering work by Cannon (1949). Visualization techniques of the root structure (Lamont, 1983; Dupuy et al., 2005) and the related biogeography (Schenk and Jackson, 2002b) led to the development of models of root architecture (Fusseder, 1983; Fitter, 1987; Berntson and Stoll, 1997; Sakai, 2001; Pagès, 2002; Salas et al., 2004; Dupuy et al., 2005), mechanisms and preferential directions of growth (Plant, 1982; Schenk and Jackson, 2002a; Lecompte et al., 2003), and functioning (e.g., Coutts, 1983; Fitter, 2002; Waisel and Eshel, 2002). Among the functional roles of roots there are transport purposes, soil exploration and exploitation, and anchorage (Coutts, 1983).
The balance between primary and adventitious roots, their degree of branching and related plasticity are also key architectural features in determining the root shape (Fitter, 1987). The latter is usually characterized by a number of measurable variables such as topology, link length, branching angles and link radius. Primary roots tend to be positively geotropic, secondary ones tend to be diageotropic and further branches to be ageotropic. Soil exploitation may induce however changes from diageotropic to positive geotropic organization. Models of the root architecture are based on topological networks (e.g., Fitter, 1987), the continuum approach (e.g., Plant, 1982) or fractal structures (see for example Feder, 1988; Takayasu, 1990; Fitter and Stickland, 1992). The latter schemes allow for a more detailed representation of actual root shapes and their associated density (e.g., Berntson and Stoll, 1997; Sakai, 2001; Salas et al., 2004), and are also suitable to describe plant and tree structures (Berntson and Stoll, 1997; Alados et al., 1999; Ferraro and Godin, 2000; Godin, 2000). Fractal approaches offer great potential for understanding and predicting root characteristics at one spatial scale from measurements at another. However, such predictions are often sensitive to the deviation of the root structure from self-similarity caused by the heterogeneity in the soil environment and the plasticity of plant response (Berntson and Stoll, 1997; Fitter, 2002; Salas et al., 2004).

\subsection{Root development in relation to soil moisture and nutrient dynamics}

In general, root morphology tends to be determined by site characteristics, soil moisture and nutrients as well as environmental conditions (Bouma et al., 2001; McMichael and Burke, 2002; Portenfield, 2002; Xie et al., 2006). After the work by Schimper (1935) substantial advancements have been made in understanding factors and mechanisms influencing both plants and their below ground biomass (see for instance Waisel and Eshel, 2002). Schenk and Jackson (2002b) proposed an analysis of rooting depths and lateral spread as a function of climate, soil and vegetation characteristics worldwide. Although the ability of plants to adapt their root length and branching complexity to soil moisture (hydrotropism) and nutrient availability is species dependent (Bouma et al., 2001), on average this feature is present for all species. At least for some species and environments, nutrient concentrations seem to exert a smaller effect on root topology than soil moisture and sediment size distribution (Fitter, 1987; Francis et al., 2005 and Pasquale et al.(2011)PasqualePasquale (Perona)). This way, plants alleviate the stress of nutrient deficiency or root competition by increasing the efficiency of nutrient acquisition and, together with the different tolerance to soil characteristics, this seems to explain the territoriality of vegetation species (Schenk and Jackson, 2002b). The maximization of the uptake rate by the root system is an expression of the ultimate performance of 
that system in exploiting the available nutrients in the soil (Robinson, 1988). Plants growing in infertile environments typically develop roots with a high root-to-shoot ratio. Xie et al. (2006) showed that for Vallisneria natans both infertile sediment and high density had similar impacts on root morphology, resulting in high specific root length. However, root distribution patterns also adjust due to the presence of neighboring plants (Casper and Jackson, 1997) and, in turn influence the local soil moisture. The latter has recently been modelled (Laio, 2006) using a stochastic approach to describe the water balance of a horizontal soil layer of infinitesimal thickness (e.g., Lai and Katul, 2000) in the presence of a vertical density distribution of roots and relating root uptake to evapotranspiration rate. The latter choice for water and nutrients uptake by roots is in accordance with some of the most common uptake models existing in literature (e.g., Feddes et al., 2001; Sperry et al., 2002), although more detailed approaches are available (Itoh and Barber, 1983; Personne et al., 2003; Roose and Fowler, 2004). On that basis a first step towards describing the root and soil moisture inter-adjustments (i.e., hydrotropism) has been proposed by Schenk (2005) and Laio (2006).

\subsection{Root anchorage in the soil and related induced cohesion}

From a mechanical viewpoint the reinforcement of soil by plant roots has been quite extensively studied mainly for steep soils and river banks (Dunaway et al., 1994; Pearce et al., 1998; Millar, 2000; Abernethy and Rutherford, 1998; Micheli and Kirchner, 2002; Sakals and Sidle, 2004; Dupuy et al., 2005; Pollen and Simon, 2005; Pollen, 2007; Eaton, 2006). Yet, knowledge of the role of below-ground biomass in stabilizing sediments and soil is limited (Gyssels and Poesen, 2003; Gyssels et al., 2005; De Baets et al., 2006) and practically unexplored for naturally non-cohesive material such as gravel and sand found on river bars and vegetated islands. Roots and soil differ enormously in their strength and physical properties (see for instance Coutts, 1983; Gregory et al., 1987; Waisel et al., 2002 and references therein). Whilst the behaviour of a tree root under tension generally follows a typical elasto-plastic curve before failure, the tensile strength of soil is practically zero in non cohesive material (Pollen, 2007). Variation may be expected with soil type heterogeneity, grain size, wetness and organic matter content. The cohesive effect of below ground biomass has been neglected often, although it is acknowledged and documented (see for instance Gyssels et al., 2005 for a review). Root networks anchor in the soil and effectively induce mechanical sediment cohesion over the surface layer of sediment bars (De Baets et al., 2006; Xie et al., 2006), crop topsoil (Bui, 1993; Gyssels and Poesen, 2003), watersheds (Prosser et al., 1995; Pearce et al., 1998) and riverbanks (Millar, 2000; Pollen-Bankhead and Simon, 2010). Erosion rates were found to be exponentially reduced by the presence of root plant communities (Dunaway et al., 1994; Gyssels et al., 2005). In rivers, additional mechanical cohesion would lead to an increase in the magnitude of the flow required for reworking the channel bed surface in comparison to sediments without vegetation. The effectiveness of flow rate magnitude in uprooting plants is usually empirically modelled, but the link to the duration and frequency of corresponding events is apparently still missing. In turn, this precludes an adequate knowledge about which and how the different hydrological and vegetation time scales are involved.

\subsection{Tree stability and vegetation uprooting}

From a functional viewpoint, the root system provides support and anchorage for the plant thus limiting uprooting (Fraser, 1962). The less cohesive is the soil matrix, the more important are the root type, age and growth patterns (Masle, 2002). For instance, windthrow is an important process in juveniles forest plantations where tree bending at the root or stem base may lead to "toppling", that is the preliminary exposure of the root apparatus (O'Laughlin, 1974). Uprooting is sometimes a sequel to the initial instability caused by toppling and eventually exacerbated by the action of either continuous or discrete erosion events (Coutts, 1983; Gyssels and Poesen, 2003; Tanaka and Yagisawa, 2009) and sliding soil masses (e.g., Stokes, 2002). The fluid mass (i.e., combined water and suspended sediments) may exert non negligible forces on the stem even at low flow velocity. At the same time, the former action is enhanced by the dynamics of flow erosion. The aforementioned mechanisms may be even more severe on river bars, because flooding leads to a simultaneous action of stem bending and localized erosion (Gran and Paola, 2001; Coulthard, 2005). The best root architecture for an anchorage system depends on the type of forces it must withstand (Coutts, 1983; Stokes et al., 1996; Dupuy et al., 2005). Thus, roots of upright plants may have a different functioning from those of climbing and protuberant plants (Ennos, 1993). Static uprooting models have generally provided evidence of some discrepancies between the calculated and the measured force to produce uprooting (Coutts, 1983). In general, resistance to uprooting increases with rooting depth and the length of lateral branches, which is a key component of anchorage (Stokes et al., 1996).

\subsection{River morphodynamics and vegetation interactions}

River morphodynamics has long been studied by geomorphologists and hydraulic engineers (e.g., Anderson et al., 1996; Seminara, 2010) who have developed models to explain pattern formation in relation to both topographic and hydrologic characteristics (Leopold and Wolman, 1960; Wolman and Miller, 1960; Rodriguez-Iturbe and A., 1997; Muneepeerakul et al., 2007, 2008b,a). Morphodynamic physically based models start from fluid mechanics and sediment transport equations (e.g., Seminara, 2010) and have 
found good applications in explaining the dynamics of meandering (e.g. see the review by Camporeale et al., 2007) and the formation and migration of river bars (Callander, 1969; Colombini et al., 1987; Tubino et al., 1999). Migration of non colonized bars has also been shown to have a convective nature (Federici and Seminara, 2004), but the role of seasonal vegetation anchoring the sediment is still unexplored. Extended studies are however available regarding the interactions and effects of either submerged or emergent vegetation on flow dynamics (Nepf, 1999; Nepf and Vivoni, 2000; Tooth and Nanson, 2000), vegetation density on canopy sublayer turbulence (Poggi et al., 2004b,a), the form of the canopy (Wilson et al., 2003) and the interaction between bedforms and vegetation (Poggi and Katul, 2007; Poggi et al., 2007). More recently, the active role of vegetation has been considered (e.g. see Gurnell and Petts, 2002; Gurnell et at, 2001; Steiger et al., 2003; Perona et al., 2008, 2009b) and coupled to the equations of morphodynamics in order to better explain the role that riparian vegetation play when colonizing point bars (Perucca et al., 2007) as well as the reciprocal interactions with river hydrology as a Markov process with dichotomic noise at both the transect and corridor scales (Perona et al., 2009a; Muneepeerakul et al., 2007). The hydrological and geomorphological significance of riparian vegetation in arid regions has been recently reviewed by Camporeale et al. (2006). As far as laboratory experiments are concerned to our knowledge only Gran and Paola (2001), Tal et al. (2004), Tal and Paola (2007) Coulthard (2005) and Perona et al. (2010) have investigated the role of vegetation in controlling morphodynamic patterns. Gran and Paola (2001) used Alfalfa grass to study the effect of vegetation on a braided stream under steady flow conditions. They observed a consistent reduction of the number of active channels after vegetation establishment. Furthermore, active channels showed a marked narrowing and deepening when compared to the experiments without vegetation. In contrast, Coulthard (2005) showed that at low vegetation densities, plants may increase braiding in streams by splitting flow and developing islands (by sediment deposition) on the lee side of the plant. However, only Tal et al. (2004) and Perona et al. (2010) investigated the interaction between flow and vegetation active growth time scales in relation to vegetation influence on morphodynamics and sediment erosion, respectively.

\section{Mechanisms of roots erosion and related conceptual modelling}

Figure 1 summarizes the scientific basis discussed in the previous section and regarding the role that vegetation roots plays in soil stabilization. Particularly, this scheme shows the origin of the numerous actions and feedbacks that characterize the water-soil-root system in the riparian zone. Taking advantage of the poor cohesion of alluvial material, and assuming nutrient distribution on river bars is not a limiting

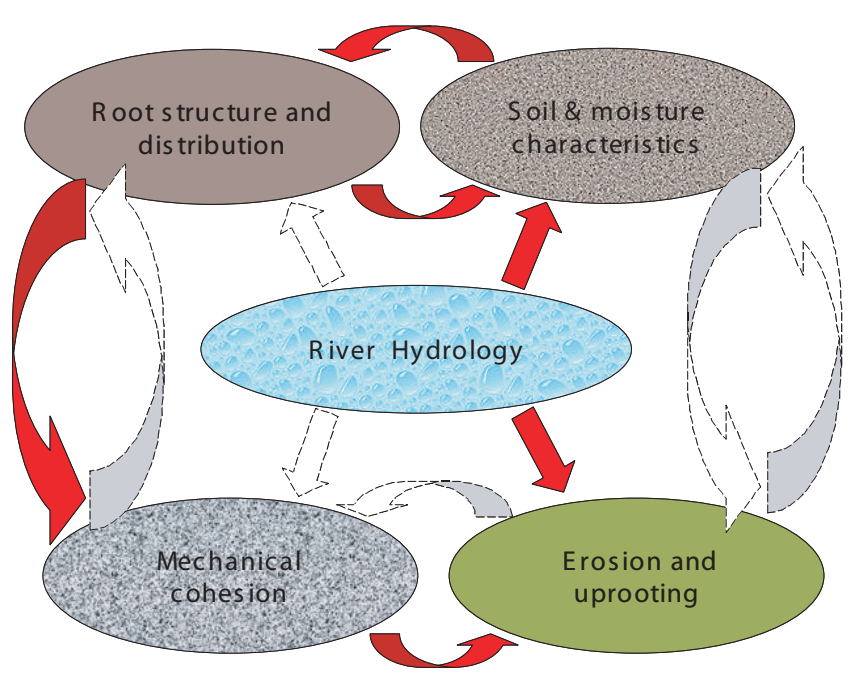

Fig. 1. Processes and interactions involved in root anchoring of pioneer alluvial vegetation in non textured e.g. alluvial soil.

factor for vegetation to grow (e.g., see the case discussed in Pasquale et al.(2011)PasqualePasquale (Perona)) we propose to simplify such a conceptual scheme, by considering red arrows to highlight the processes that are mostly relevant for erosion dynamics of riparian pioneer vegetation in non cohesive sediment as investigated in this work.

In order to inquire the characteristic time scales with which vegetation uprooting occurs as a function of vegetation stage and flood characteristics, we consider two main mechanisms of vegetation uprooting (Fig. 2). The physical condition at the base of the first mechanism (henceforth referred to as "Type I") is the equilibrium between the vectorial sum of the buoyancy and drag forces of the stream on the above ground biomass (stem and canopy), indicated by red arrows, which has to be balanced by the resistance due to root anchoring (orange arrows). Breaking such an equilibrium leads to a practically instantaneous uprooting of the whole plant (Fig. 2, Type I). Therefore this mechanism is mainly relevant to juvenile vegetation (e.g., seedling and sprouted LWDs) with relative short and simple branching root architecture. The big filled arrows represent the total resulting force favoring erosion and anchoring respectively.

The second uprooting mechanism (henceforth referred to as "Type II") concerns with the removal of more mature vegetation with substantial root biomass and branching architecture (Fig. 2, Type II). Because of the more pronounced root system compared to that of juvenile plants, the anchoring of the mature plant within the alluvial sediment grows strongly nonlinearly as a function of root length (orange arrows). For textured soil, Pollen-Bankhead and Simon (2010) quantified the reduction of local scouring in the presence of increasing below-ground biomass (transparent red arrows). Therefore, uprooting must be the result of local erosion of the riverbed around the plant, the effect of which is to gradually 

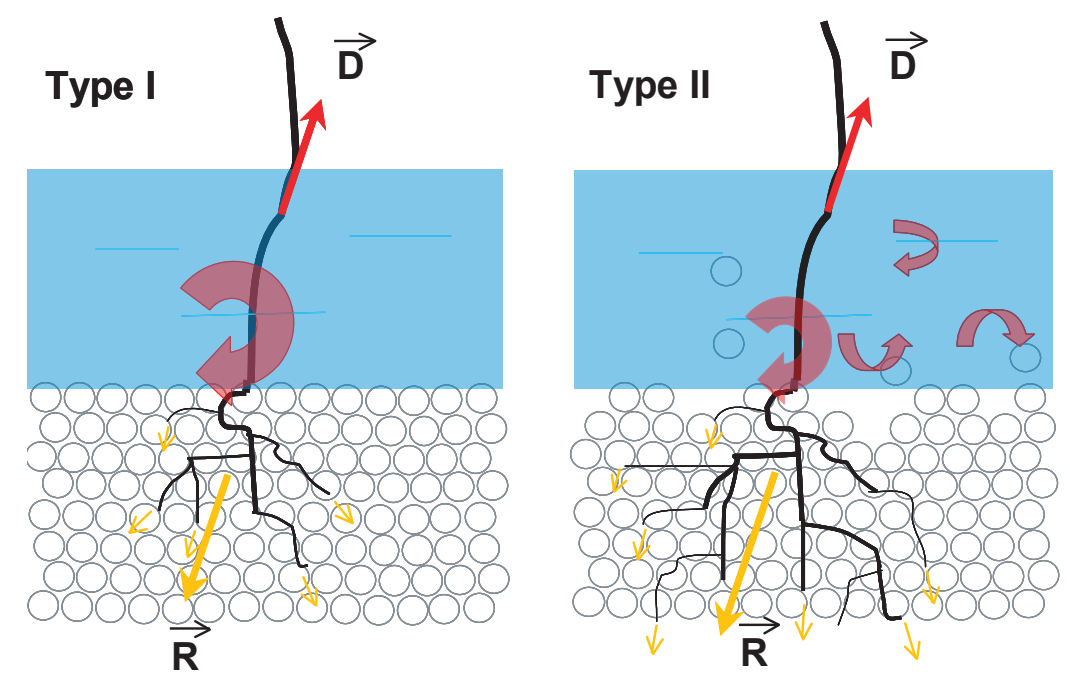

Fig. 2. Mechanisms of root erosion by flow: Type I is caused by flow-induced drag force. It is assumed to occure rather instantanious and to be relevant to young vegetation. Type II is a combination of local sediment erosion around the plant decreasing the anchorng force until drag force prevails. Type II is more complex, therefore occuring on a larger timescale and relevant to vegetation with more pronounced root systems.

expose the root to the flow thus reducing the anchoring resistance. The process continues until the root resistance is greater than the pullout action due to drag force as described for the Type I mechanism. The combined action of erosion triggering the root system toward a critical resistance stage introduces a time delay due to morphodynamic processes, which is the main difference between the two types of mechanisms. However, the effect of the delay is to cause a partially exposed root not necessarily to die off. The root system can potentially grow further before the arrival of a successive flood, thus giving rise to interesting competition dynamics as conceptually depicted later ahead.

\subsection{Mechanism of roots erosion Type I}

The model for erosion of young vegetation by flow is conceptualized by the 4-quadrants Fig. 3. We first discuss a purely deterministic picture of the erosion dynamics.

Consider the quadrant indicated with 1 in Fig. 3. The cartesian axes report the intertime $t_{\mathrm{r}}$ with which a given river discharge $Q_{\mathrm{C}}$ starts inundating a certain river transect, assumed to be populated by early germinated vegetation. Such a flow is clearly a function of the local topography (i.e. elevation). For the sake of clarity we consider here the shoreline inundated by the modal flow $Q_{\mathrm{C}}=Q_{\text {modal }}$ in correspondence of which the intertime function has a minimum. Seedling or LWDs sprouting in proximity of such a shoreline will be inundated by any flow $Q>Q_{\mathrm{C}}$ with an intertime between two equal disturbance that increases with the magnitude of $Q$. For a non-equilibrium topography, depending on the trunkdiameter-to-sediment-size ratio $D_{\mathrm{t}} / d_{50}$ (Melville and Sutherland, 1988), Type I erosion is limited by a certain flow mag- nitude at which sediment particles start to move and hence Type II root erosion mechanism applies. A flow $Q>Q_{\mathrm{C}}$ generates a velocity field, which induces an effective drag force $D$ on the young above-ground biomass. This relationship is shown by the exemplary curve in quadrant 2. Although for flow past rigid non-porous obstacles a consistent theory is available (e.g., Batchelor, 2000), for flexible obstacles only experimental results are actually available. For the sake of illustration the concept, for the time being we assume a linear relationship between drag force and flow magnitude for submerged vegetation as inferred after the experimental investigations of Xavier et al. (2010) and FathiMaghadam and Kouwen (1997). Eventually, the drag force that is induced by a flood of a certain interarrival time requires seedling roots to oppose a given resistance $R$ via mechanical anchoring. Root reinforcement depends on the amount and strength of the roots that are present in the soil as indicated by Pollen (2007). This relationship is shown in quadrant 3 as a function of an effective root length $L_{\mathrm{r}}$. In textured soil, with increasing root length also the root diameter does, and the force $F_{\mathrm{P}}$ needed to pullout the plant does increase following a power law as suggested by Pollen (2007):

$F_{\mathrm{P}}=S \cdot L \cdot 2 \pi r$

where $S$ representing the soil shear strength, $L$ and $r$ root length and radius respectively. Since experimental data for non-cohesive material are not available to our knowledge, we illustrate our model philosophy by adopting the nonlinear relation recommended by Pollen (2007). We complete the quadrant 4 of the model by representing how the effective root length grows within time intervals equal to $t_{\mathrm{r}}$. Exemplary mean root growth curves are labelled with letters $A$ 

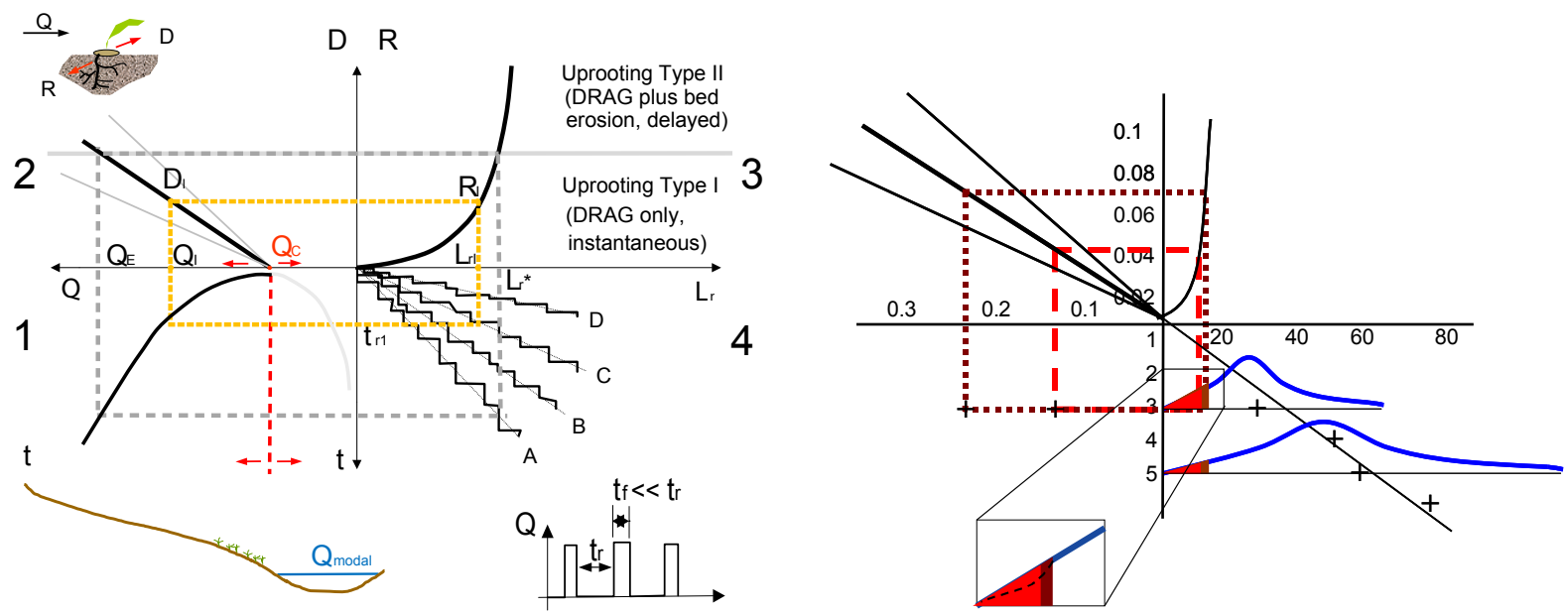

Fig. 3. Left: conceptual model of frictional root erosion relating forces and processes involved in the Type I root erosion mechanism. $Q$ : flow at certain elevation of river section; $D$ : effective flow-induced drag; $R$ : effective resistance to uprooting in wet conditions; $L$ : root factor including root length and architecture. Right: stochastic conceptualization of Type I root erosion mechanism.

to $D$, which parameterize the mean growth rate. Such curves refer to experiments conducted with Avena sativa (e.g., Jiang et al., 2009; Perona et al., 2010).

The proposed model conceptualizes the fact that a flow with magnitude $Q_{\mathrm{I}}$ (Fig. 3) and interarrival time $t_{\mathrm{I}}$ impacts the growing vegetation at the site with a drag force $D_{\mathrm{I}}$. Hence, young vegetation will be able to withstand such a drag flow only by opposing a resistance to uprooting $R_{\mathrm{I}} \geq D_{\mathrm{I}}$. In turn, this requires a minimal root growth rate to generate enough below-ground biomass in the time lapse $t_{\mathrm{r}}$, which in the example of Fig. 3 corresponds to the curve labelled with the letter C. Only plants with a root growth rate higher than the curve "C" will survive, viceversa the force balance is not satisfied and uprooting will occur practically instantaneously. Although simplified, this deterministic view expresses the concept that survival to uprooting is a competition dynamics between growth rate and frequency and magnitude of flood disturbances.

The real picture is more complex and requires a stochastic framework, where drag $D$, and resistance $R$ as a function of root length $L_{\mathrm{r}}$ have to be interpreted as mean values of a general stochastic ensemble. Figure 3 (right panel) shows the result of the stochastic interpretation of the mechanism Type I. That is, consider the distribution of vegetation growing on alluvial bedforms, which keeps growing with a time dependent statistical distribution. In the exemplary case that periodic disturbances of fixed magnitude (e.g., dashed line) flood the vegetated area, then the uprooted biomass is sampled from the left tail (i.e., the colored area) of the distribution of the vegetation growing in situ. Because of the intrinsic stochastic nature of the process not all "weak" vegetation will be removed at once. This means that the tail of the vegetation growing in situ will be reduced and correspondingly the distribution of the uprooted biomass will originate from this "sampling" operated by the flood. The uprooting process by the Type I mechanism will eventually end as a result of the growing process (gradually shifting the distribution toward higher root length values) and the action of floods, which remove the weaker material. The expected effect of disturbances with higher magnitude is to originate a distribution of the uprooted material with a bigger mean, and eventually to anticipate the end of the process.

Although simple, the mechanism we described so far is useful to understand the role of floods as natural "filters", which may select the survival of young individuals within species and among species. This would explain the initial colonization dynamics of pioneer vegetation on exposed bars in both natural and restored river corridors.

\subsection{Mechanism of roots erosion Type II}

The erosion mechanism Type I implicitly assumes that the uprooting process occurs instantaneously as a result of a simple balance of the involved forces, and that no significant bed erosion would reduce the anchoring by gradually exposing the root system. In practice, the existence of a flowrate $Q_{\text {E }}$ (see Fig. 3) corresponding to incipient bedload transport conditions for the local topography implies that flood events of magnitude $Q>Q_{\mathrm{E}}$ do not remove longer roots by pure drag only. Root resistance as a function of root length likely grows in a nonlinear way with the associated root length because of the complex architecture that anchors the sediment. Eventually, for more mature vegetation such a mechanical anchoring will easily go "out of scale" even with respect to the potential maximum drag induced by the largest historical flood. Hence, uprooting of mature vegetation requires the onset of the delayed Type II mechanism which is described ahead. 

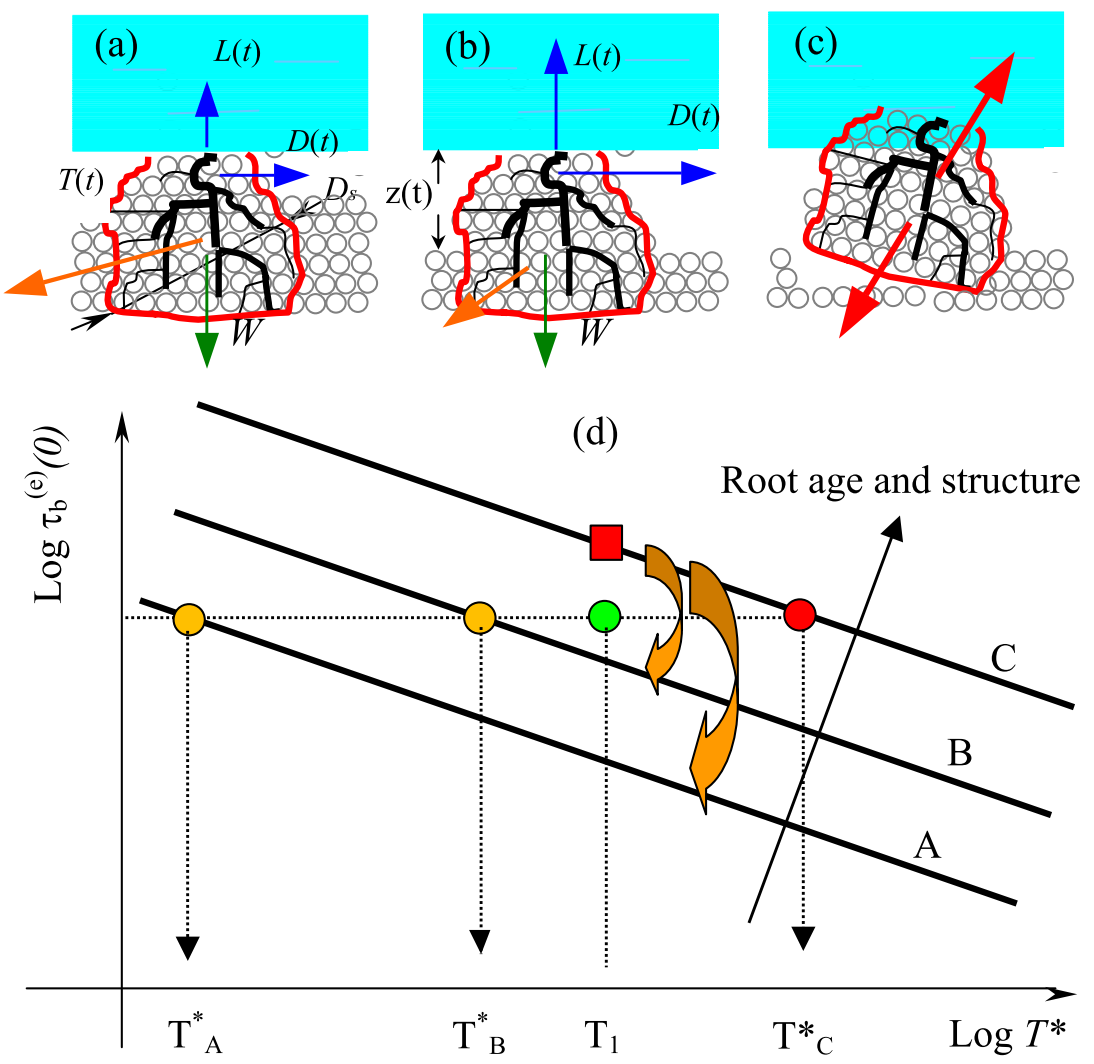

Fig. 4. Conceptual model of Type II root erosion. Subpanels (a) to (c) illustrate the gradual decrease of anchoring by local erosion until uprooting; (d) describes the interaction of flow magnitude (wall shear stress $\tau_{\mathrm{b}}$ ) and flow duration $(T$ ) in order to uproot vegetation of certain maturity (curves A-C, A representing the least, $\mathrm{C}$ the most mature vegetation).

The conceptual model that we propose aims at illustrating the fundamental time scales of the interactions between erosional flow and soil reinforcement by root anchoring. Following Fig. 4a, the root system anchors a volume of sediments which can be idealized as a macroparticle of characteristic diameter $D_{\mathrm{s}}$ growing with the time scale $T_{\mathrm{g}}$. During floods scouring gradually exposes the roots thus reducing the effective length determining the anchoring, lift $L(t)$ and drag $D(t)$ forces grow in spite of a reduction of the mechanical anchoring $R$ and the effective weight $W$ of the original macroparticle. The temporal trend of such forces proceeds until the anchoring equates the forces favoring erosion and thus uprooting is determined. We summarize this picture as a plot (Fig. 4d) reporting the duration $T^{*}$ that a given flow requires to erode a certain root structure, which can be associated to a certain vegetation maturity stage (curves A-C, $\mathrm{A}$ representing the least, $\mathrm{C}$ the most mature vegetation). A similar plot is known in biomechanics as Leverett-Tillmann diagram (Leverett et al., 1972; Tillmann et al., 1984; Suresh, 1998), whose original formulation was meant to describe the mechanical fatigue induced by a continuously applied (flow) shear stress on red cells until the rupture of their external membrane.
We conjecture whether a similar mechanism can be adopted to describe the delayed erosion process of mature vegetation in relation to flow magnitude, frequency and duration. We do not consider deposition dynamics and their effect on the erosion of vegetation, and again we begin with commenting on a purely deterministic picture of the problem. Particularly interesting is indeed a discussion among the involved time scales, which can be summarized as follows (Fig. 4d). Let us consider a flow determining a wall shear stress $\tau_{\mathrm{b}}$ responsible for scouring the river bed locally, and that such a gradual action will take a time $T_{\mathrm{C}}^{*}$ to reduce the effective anchoring of a root structure $\mathrm{C}$ to a critical value where drag prevails on the resistance thus producing uprooting. If such a flow only lasts for a time $T_{1}<T_{\mathrm{C}}^{*}$, then it will determine an erosion effect with consequent partial exposure of the root system that is equivalent to reclassify that vegetation as of younger ages, e.g. B or A depending on the amount of scouring. If roots do not grow further between the arrival of two successive floods, then the next disturbance of equal magnitude will only require a duration $T_{\mathrm{B}}^{*}$ or $T_{\mathrm{A}}^{*}$ (orange dots), respectively in order to produce uprooting. That is, uprooting might occur either at the same flow magnitude as for the green dot but for longer flow duration (red dot), or 


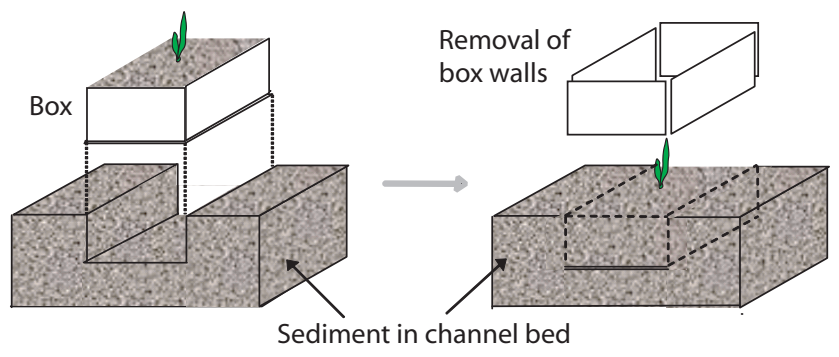

Fig. 5. Box system to insert germinated seedlings into the flume bed.

at a higher flow magnitude for the same duration (red triangle).

Riparian vegetation in nature is likely to be removed by this type of mechanism, evidence of which has also been given in field experiments of cutting transplantation dynamics in restored river corridors (e.g., see Pasquale et al.(2011)PasqualePasquale (Perona)). That paper clearly documents a quite rare image of root system partially exposed by a flood, which has later continued to grow. This supports the idea that understanding the time scales where flow and vegetation actually interact is of fundamental importance to predict the evolution of restored river corridors. Our conceptual model is therefore meant to be a first step useful to help designing future laboratory experiments aimed at corroborating our conjectures with data, and to develop quantitative mechanistic models possibly applicable at the actual scale.

\section{Experimental evidence}

In the previous Section we conjectured the existence of characteristic scales between root length, flow magnitude and time to erosion that discriminate between the Type I and Type II mechanisms of erosion. We performed some preliminary laboratory experiments with non-cohesive sand to prove the existence of the two mechanisms and the substantially instantaneous time scale that characterize uprooting Type I (Chollet, 2009). Compared to field scale experiments, laboratory experiments are particularly useful because they allow to collect and analyze the eroded material (sediment and plants) at the bottom of the flume.

Our laboratory setup is quite simple accounting mainly of a small flume (channel width: $40 \mathrm{~cm}$; total length $4 \mathrm{~m}$; length of the sand bed reach: $117 \mathrm{~cm}$, sand depth: $50 \mathrm{~cm}$, slope: $1.3 \%$ ), a volumetric flow measurement device and a high resolution (temporal) video camera. Quartz sand $\left(d_{50}=0.56\right.$, $d_{90}=0.68 \mathrm{~mm}$ ) was used as non-cohesive sediment. Seeds of Avena Sativa (five per run) were first marked with different colors, and then planted within a rectangular moving box with removable walls (Fig. 5). Seeds are initially covered with a thin layer of sand (about $1 \mathrm{~mm}$ ) in order to keep

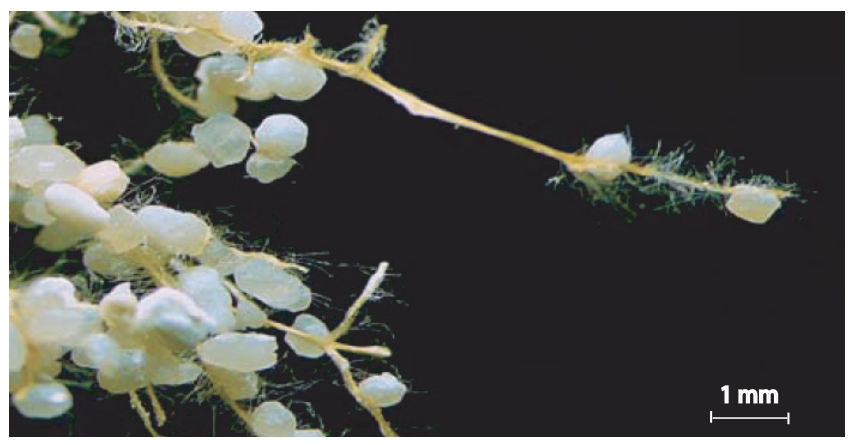

Fig. 6. Root system of Avena Sativa showing the development of hairy roots which may lead to sediment entrapment.

the moisture and favor germination. Avena Sativa was chosen because it germinates quickly (about $2-3$ days at $20^{\circ} \mathrm{C}$ ), and rapidly develops long root systems with 1 to 3 primary roots (Jiang et al., 2009). Under water stress conditions Avena Sativa developes hairy roots which contribute to sediment anhoring (Fig. 6). In the experiment, germination was achieved after 2-3 days with about $1 \mathrm{~cm}$ long roots at day 3 . Before the experiment took place, the moving box was inserted within the downstream second half of the channel bed, the lateral walls carefully removed and the soil gently recompacted to a flat bed without disturbing the germinated seedlings. Seedlings would eventually be organized along a transect perpendicular to the flow direction (Fig. 7a). This technique allowed us to grow seeds out of the flume, thus speeding up the whole procedure and obtain a statistically significant number of experiments.

When the experiment started, the bed was first carefully saturated without inundating the seedlings, then the flow was increased and kept to a constant value $\left(0.8,1.251 \mathrm{~s}^{-1}\right)$ for a maximum of $30 \mathrm{~min}$. The first $20-30 \mathrm{~cm}$ at the bottom of the sandy reach were used as sediment source, albeit the bedload transport was quite low for such experimental conditions. After $30 \mathrm{~min}$ the flow was stopped and the eroded material recovered at the bottom end of the flume. The lapse time to erosion for each eroded seedling was eventually reconstructed from the recorded video by visually identifying their respective colors. 20 runs were performed per each flow magnitude, the root structure of the uprooted and of the non uprooted seedlings was statistically analyzed in relation to flow magnitude and time to erosion.

The uprooted material developed up to one primary root in $56 \%$ of the cases and more than 1 root in $44 \%$. On the contrary, the non uprooted material showed a percentage of individuals with at least one root equal to $18 \%$, whereas those with more than one root were as much as $82 \%$. At present we are not able to quantify the role of additional roots on the effective anchoring, so we only acknowledge that this might have an effect on the results. In the following we will only use the main root as explanatory variable and not its 
branching architecture, which although simple at early stages might already trap sediments by means of hairy roots (Fig. 6).

The statistical analysis of our results reveal the existence of the two mechanisms of uprooting. Figure $7 \mathrm{~b}$ shows the main root length for all seedlings, particularly black circles refer to the eroded seedlings, whereas gray diamonds to the non eroded ones. We computed a reference threshold value for the main root length, above which seedlings statistically withstand the drag force for the given flow magnitude and duration of the experiment, and below which they are actually removed. This line corresponds to the dot-dashed line for a root length of $8 \mathrm{~mm}$ discriminating between uprooted and non uprooted seedlings at an equal confidence level of $70 \%$

As far as the removed material is concerned, Fig. 7c plots the time to erosion in relation to the root length and shows the existence of a short and a longer temporal scale at which uprooting occurs. Seedlings with a root length shorter than $7 \mathrm{~mm}$ are statistically uprooted on short times (i.e., within the first $60 \mathrm{~s}$ ) in about $90 \%$ of the cases. However, we see that if the threshold would be set at $12 \mathrm{~mm}$, i.e. just leaving out of the count the two eroded samples with root length equal to $20 \mathrm{~mm}$ requiring more than $3 \mathrm{~min}$ to be uprooted, then the percentage of instantaneous removal would still be about $68 \%$. These considerations lead us to suppose that for the given flowrate a Type I mechanism satisfactorily explains the removal of seedlings with root length below $12 \mathrm{~mm}$, whereas uprooting longer roots would require a prolonged action where presumably also local bed erosion plays a role in the spirit of the Type II mechanism.

\section{Conclusions}

In the time when river restoration, renaturalization, and rehabilitation are important management measures to recover the quality of riverine environments worldwide (Bernhardt et al., 2007), it is mandatory to understand mechanistic rules at the base of coupled ecohydrological and morphodynamic processes. Among these rules, particularly important is the role played by seed germination and vegetative reproduction of LWD in relation to flood statistics to contribute to the colonization and spreading of riparian pioneer species (Edwards et al., 1999). The survival of riparian vegetation at its early stage of growth is of great importance in order to assess the long term morphodynamic evolution of restored river corridors. The reason is the multiple functions that vegetation plays in such environments according to their vulnerability and in response to human interventions (Decamps et al., 1988; Hughes, 1997; Tockner and Stanford, 2002). Ultimately, many riparian dynamics involve feedbacks with vegetation at all its stage of growth, where sediment stabilization via root anchoring ultimately dictate the ability of vegetation to colonize and grow in relation to flood disturbances.
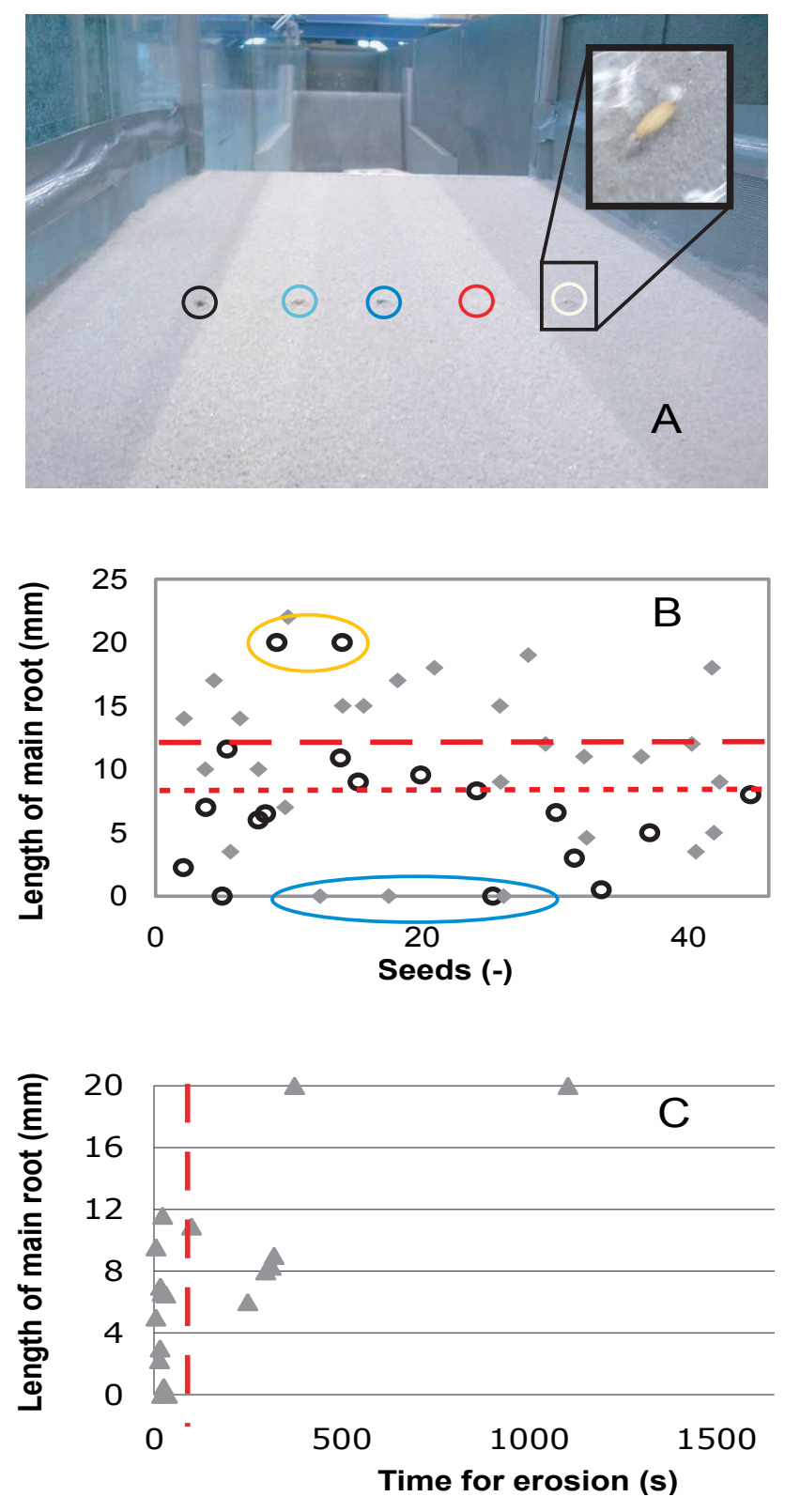

Fig. 7. (A): experimental setup in flume channel; circles indicate colored seedlings.; (B): length of main root of eroded (black circles) and not eroded (gray triangles) seedlings; the dashed line indicates the threshold rootlength for Type I (shorter main rot) and Type II (longer main root) erosion (C): time needed for erosion and length of main root for eroded seedlings; vertical dashed line indicating threshold between instantanious Type I and rather delayed Type II erosion.

This work started from a literature review on the subject of vegetation root erosion by flow with the purpose of identifying two key mechanisms that potentially emerge in the presence of non cohesive sediment, and that could help explaining links and roles of the hydrologic and biologic time scales. 
Particularly, we focused on the uprooting of pioneer vegetation growing roots within alluvial non-cohesive sediment such that forming river bars and islands. We proposed two conceptual models corroborated by some preliminary laboratory experiments to prove that non-cohesive sediment indeed enhances the presence of two different time scales of root erosion by flow, which are the essence of the two proposed mechanisms. The consequences of having the one or the other mechanism prevailing are relevant to vegetation at the different life stages. One striking result of the Type I mechanisms is that floods would act as selective filters of young vegetation within and among species. The role of Type I erosion would now be worth testing on the experimental data sets of Perona et al. (2010). Similarly, an experimental verification and modelling for the Type II mechanism is an open issue that will be investigated by the authors in the future.

Acknowledgements. This article has been sponsored by the Swiss National Science Foundation Research Project ROOTEDNESS, Grant No. 200021-125273/1.

Edited by: E. Durisch-Kaiser

\section{References}

Abernethy, B. and Rutherford, I. D.: Where Along a River's Length Will Vegetation Most Effectively Stabilise Stream Banks?, Geomorphology, 23, 55-75, 1998.

Alados, C. L., Escos, J., Emlen, J. M., and Freeman, D. C.: Characterization of Branch Complexity by Fractal Analyses, pMID: 10572029, Int. J. Plant Sci., 160, S147-S155, doi:10.1086/314220, 1999.

Anderson, M. G., Walling, D., and Bates, P. D.: Floodplain Processes, John Wiley and Sons, Chichester, 1996.

Batchelor, G.: An introduction to fluid dynamics, Cambridge University Press, Cambridge, 2000.

Bernhardt, E., Sudduth, E., Palmer, M., Allan, J., Meyer, J., Alexander, G., Follastad-Shah, J., Hassett, B., Jenkinson, R., Lave, R., Rumps, J., and Pagano, L.: Restoring rivers one reach at a time: results from a survey pf US river restoration practitioners, Restor. Ecol., 15, 482-493, 2007.

Berntson, G. M.: Topological scaling and plant root system architecture: developmental and functional hierarchies, New Phytologist, 135, 621-634, doi:10.1046/j.1469-8137.1997.00687.x, 1997.

Berntson, G. M. and Stoll, P.: Correcting for finite spatial scales of self-similarity when calculating fractal dimensions of real-world structures, Proc. Biol. Sci., 264, 1531-1537, 1997.

Bouma, T. J., Nielsen, K. L., Van Hal, J., and Koutstaal, B.: Root system topology and diameter distribution of species from habitats differing in inundation frequency, Funct. Ecol., 15, 360-369, 2001.

Bui, E. N. and Box, J. J.: Growing corn root effects on interrill soil erosion, Soil Sci. Soc. Am. J., 57, 1066-1070, 1993.

Callander, R. A.: Instability and river channels, J. Fluid Mech., 36, 465-480, doi:10.1017/S0022112069001765, 1969.

Camporeale, C., Perona, P., and Ridolfi, L.: Hydrological and geomorphological significance of riparian vegetation in arid regions, in: Dryland Ecohydrology, edited by: D'Odorico, P. and Porporato, A., Springer, Dordrecht, 161-180, 2006.

Camporeale, C., Perona, P., Porporato, A., and Ridolfi, L.: Hierarchy of models for meandering rivers and related morphodynamic processes, Rev. Geophys., 45, RG1001, doi:10.1029/2005RG000185, 2007.

Cannon, W.: A tentative classification of root systems, Ecology, 30, 542-548, 1949.

Casper, B. B. and Jackson, R. B.: Plant competition underground, Ann. Rev. Ecol. Syst., 28, 545-570, doi:10.1146/annurev.ecolsys.28.1.545, 1997.

Chollet, E.: Processing and analysis of data from river ecohydrology laboratory experiments, Master's thesis, ETH Zurich, 2009.

Colombini, M., Seminara, G., and Tubino, M.: Finiteamplitude alternate bars, J. Fluid Mech., 181, 213-232, doi:10.1017/S0022112087002064, 1987.

Coulthard, T.: Effects of vegetation on braided stream pattern and dynamics, Water Resour. Res., 41, W04003, doi:10.1029/2004WR003201, 2005.

Coutts, M. P.: Root architecture and tree stability, Plant Soil, 71, 171-188, 1983.

De Baets, S., Poesen, J., Gyssels, G., and Knapen, A.: Effects of grass roots on the erodibility of topsoils during concentrated flow, Geomorphology, 76, 54-67, doi:10.1016/j.geomorph.2005.10.002, 2006.

Decamps, H., Fortune, M., Gazelle, F., and Pautou, G.: Historical Influence of Man and Riparian Dynamics of a Fluvial Landscape, Landscape Ecol., 1, 163-177, 1988.

Dunaway, D., Swanson, S. R., Wendel, J., and Clary, W.: The effect of herbaceous plant communities and soil textures on particle erosion of alluvial streambanks, Geomorphology, 9, 47-56, doi:10.1016/0169-555X(94)90030-2, 1994.

Dupuy, L., Fourcaud, T., and Stokes, A.: A numerical investigation into factors affecting the anchorage of roots in tension, Eur. J. Soil Sci., 56, 319-327, 2005.

Eaton, B.: Bank stability analysis for regime models of vegetated gravel bed rivers, Earth Surf. Proc. Land., 31, 1438-1444, 2006.

Edwards, P. J., Kollmann, J., Gurnell, A. M., Petts, G. E., Tockner, K., and Ward, J. V.: A Conceptual Model of Vegetation Dynamics on Gravel Bars of a Large Alpine River, Wet. Ecol. Man., 7, 141-153, 1999.

Ennos, A. R.: The Scaling of Root Anchorage, J. Theor. Biol., 161, 61-75, doi:10.1006/jtbi.1993.1040, 1993.

Fathi-Maghadam, M. and Kouwen, N.: Nonrigid, Nonsubmerged, Vegetative Roughness on Floodplains, J. Hydraul. Eng., 123, 5157, 1997.

Feddes, R. A., Hoff, H., Bruen, M., Dawson, T., de Rosnay, P., Dirmeyer, P., Jackson, R. B., Kabat, P., Kleidon, A., Lilly, A., and Pitman, A. J.: Modeling Root Water Uptake in Hydrological and Climate Models, B. Am. Meteorol. Soc., 82, 2797-2809, doi:10.1175/15200477(2001)082;2797:MRWUIH $i 2.3 . C O ; 2,2001$.

Feder, J.: Fractals, Plenum Press, New York, 1988.

Federici, B. and Seminara, G.: On the convective nature of bar instability, J. Fluid. Mech., 487, 125-145, 2004.

Ferraro, P. and Godin, C.: A distance measure between plant architectures, Ann. Forest Sci., 57, 445-461, 2000.

Fitter, A.: Characteristics and functions of root systems, in: Plant roots: The Hidden Half, Marcel Dekker, New York, 21-50, 2002. 
Fitter, A. and Stickland, T.: Fractal Characterization of Root System Architecture, Funct. Ecol., 6, 632-635, 1992.

Fitter, H.: An Architectural Approach to the Comparative Ecology of Plant Root Systems, New Phytol., 106, 61-77, 1987.

Francis, R. A., Gurnell, A. M., Petts, G. E., and Edwards, P. J.: Survival and growth responses of Populus nigra, Salix elaeagnos and Alnus incana cuttings to varying levels of hydric stress, Forest Ecol. Manage., 210, 291-301, doi:10.1016/j.foreco.2005.02.045, 2005.

Fraser, A. I.: The Soil and Roots as Factors in Tree Stability, Forestry, 35, 117-127, doi:10.1093/forestry/35.2.117, 1962.

Fusseder, A.: A method for measuring length, spatial distribution and distances of living roots in situ, Plant Soil, 73, 441-445, doi:10.1007/BF02184323, 1983.

Godin, C.: Representing and encoding plant architecture: A review, Ann. Forest Sci., 57, 413-438, doi:10.1051/forest:2000132, 2000.

Gran, K. and Paola, C.: Riparian Vegetation Controls on Braided Stream Dynamics, Water Resour. Res., 37, 3275-3283, 2001.

Gregory, P., Lake, J., and Rose, D.: Root development and function, Cambridge University Press, Cambridge, UK, 1987.

Gurnell, A. and Petts, G.: Island-dominated landscapes of large floodplain rivers, a European perspective, Freshwater Biol., 47, 581-600, 2002.

Gurnell, A., Petts, G., Hannah, D., Smith, B., Edwards, P., Kollmann, J., Ward, J., and Tockner, K.: Riparian vegetation and island formation along the gravel-bed Fiume Tagliamento, Italy, Earth Surf. Proc. Land., 26, 31-62, 2001.

Gyssels, G. and Poesen, J.: The importance of plant root characteristics in controlling concentrated flow erosion rates, Earth Surf. Proc. Land., 28, 371-384, 2003.

Gyssels, G., Poesen, J., Bochet, E., and Li, Y.: Impact of plant roots on the resistance of soils to erosion by water: a review, Prog. Phys. Geogr., 29, 189-217, doi:10.1191/0309133305pp443ra, 2005.

Hughes, F. M. R.: Floodplain Biogeomorphology, Prog. Phys. Geogr., 21, 501-529, 1997.

Itoh, S. and Barber, S.: A numerical solution of whole plant nutrient uptake for soil-root systems with root hairs, Plant Soil, 70, 403413, doi:10.1007/BF02374895, 1983.

Jackson, R. B., Canadell, J., Ehleringer, J. R., Mooney, H. A., Sala, O. E., and Schulze, E. D.: A global analysis of root distributions for terrestrial biomes, Oecologia, 108, 389-411, doi:10.1007/BF00333714, 1996.

Jiang, Z., Perona, P., Francis, R., Molnar, P., and Burlando, P.: An experimental comparison of silica gel and quartz sand grains as sediment media for growing vegetation at the laboratory scale, Aquat. Sci., 3, 350-355, 2009.

Johnson, W. C.: Tree Recruitment and Survival in Rivers: Influences of Hydrological Processes, Hydrol. Process., 14, 30513074, 2000.

Karrenberg, S., Blaser, S., Kollmann, J., Speck, T., and Edwards, P.: Root anchorage of saplings and cuttings of woody pioneer species in a riparian environment, Funct. Ecol., 17, 170-177, 2003.

Lai, C.-T. and Katul, G.: The dynamic role of root-water uptake in coupling potential to actual transpiration, Adv. Water Resour., 23, 427-439, doi:10.1016/S0309-1708(99)00023-8, 2000.

Laio, F.: A vertically extended stochastic model of soil mois- ture in the root zone, Water Resour. Res., 42, W02406, doi:10.1029/2005WR004502, 2006.

Lamont, B.: Root hair dimensions and surface/volume/weight ratios of roots with the aid of scanning electron microscopy, Plant Soil, 74, 149-152, doi:10.1007/BF02178753, 1983.

Lecompte, F., Ozier-Lafontaine, H., and Pages, L.: An analysis of growth rates and directions of growth of primary roots of fieldgrown banana trees in an andisol at three levels of soil compaction, Agronomie, 23, 209-218, 2003.

Leopold, L. B. and Wolman, M. G.: River meanders, Geol. Soc. Am. Bull., 71, 769-793, 1960.

Leverett, L., Lynch, E., Alfrey, C. P., and Hellums, J.: Red bloodcell damage by shear-stress, Biophys. J., 12, 257-273, 1972.

Mahoney, J. M. and Rood, S. B.: Streamflow requirements for cottonwood seedling recruitment: An integrative model, Wetlands, 18, 634-645, 1998.

Masle, J.: High soil strength: Mechanical forces at play on root morphogenesis and in root: Shoot signaling, in: Plant roots: the hidden half, Marcel Dekker, 2002.

McMichael, B. and Burke, J.: Temperature effects on root growth, in: Plant roots: the hidden half, Marcel Dekker, 2002.

Melville, B. W. and A. J. Sutherland: Design method for local scour at bridge piers, J. Hydraul. Eng.-(ASCE), 114(10), 1210-1226, 1988.

Micheli, E. R. and Kirchner, J. W.: Effects of wet meadow riparian vegetation on streambank erosion, 2. Measurements of vegetated bank strength and consequences for failure mechanics, Earth Surf. Proc. Land., 27, 687-697, 2002.

Millar, R. G.: Influence of bank vegetation on alluvial channel patterns, Water Resour. Res., 36, 1109-1118, doi:10.1029/1999WR900346, 2000.

Moggridge, H. and Gurnell, A.: Hydrological controls on the transport and deposition of plant propagules within riparian zones, River Res. Appl., 26, 512--527, 2010.

Muneepeerakul, C. P, Rinaldo, A., and Rodrigez-Iturbe, I.: Effects of river flow scaling properties on riparian width and vegetation biomass, Water Resour. Res., 43, 2406, doi:10.1029/2007WR006100, 2007.

Muneepeerakul, C. P. F. M. W., Tamea, S., Rinaldo, A., and Rodriguez-Iturbe, I.: Coupled hydrologic and vegetation dynamics in wetland ecosystems, Water Resour. Res., 44, 7421,doi:10.1029/2007WR006100, 2008a.

Muneepeerakul, C. P., Rinaldo, A., Levin, S., and Rodrigez-Iturbe, I.: Signatures of vegetational functional diversity in river basins, Water Resour. Res., 44, 1431, doi:10.1029/2007WR006153, 2008b.

Nepf, H.: Drag, Turbulence, and Diffusion in Flow Through Emergent Vegetation, Water Resour. Res., 35, 479-489, 1999.

Nepf, H. and Vivoni, E.: Flow structure in depth-limited, vegetated flow, J. Geophys. Res., 105, 28547-28557, 2000.

O'Laughlin, C.: The effect of timber removal on the stability of forest soils, J. Hydrol., 13, 121-134, 1974.

Pagès, L.: Modelig root system architecture, in: Plant roots: the hidden half, Marcel Dekker, 2002.

Palmer, M., Allan, J., Meyer, J., and Bernhardt, E.: River restoration in the twenty-first century: dataand experiential knowledge to inform future efforts, Restor. Ecol., 15, 472-481, 2007.

Pasquale, N., Perona, P., Schneider, P., Shrestha, J., Wombacher, A., and Burlando, P.: Modern comprehensive approach to mon- 
itor the morphodynamic evolution of a restored river corridor, Hydrol. Earth Syst. Sci., 15, 1197-1212, doi:10.5194/hess-151197-2011, 2011.

Pearce, R., Trlica, M., Leininger, W., Mergen, D., and Frasier, G.: Sediment movement through riparian vegetation under simulated rainfall and overland flow, J. Range Manage., 51, 301-308, 1998.

Perona, P., Molnar, P., Savina, M., and Burlando, P.: Stochastic sedimentvegetation dynamics in an Alpine braided river, in: Proceedings of the symposium Sediment Dynamics in Changing Environments, IAHS Pub. 325, 266-274, 2008.

Perona, P., Molnar, P., Savina, M., and Burlando, P.: An observation-based stochastic model for sediment and vegetation dynamics in the floodplain of an Alpine braided river, Water Resour. Res., 45, W09418, doi:10.1029/2008WR007550, 2009a.

Perona, P., Camporeale, C., Perucca, E., Savina, M., Molnar, P., Burlando, P., and Ridolfi, L.: Modelling river and riparian vegetation interactions and related importance for sustainable ecosystem management, Aquat. Sci., 71, 266-278, doi:10.1007/s00027-009-9215-1, 2009b.

Perona, P., Molnar, P., Jiang, Z., Camporeale, C., Perucca, E., Francis, R., and Gurnell, A.: The role of hydrologic disturbances on biomass erosion dynamics: first results from RIVERINE experiments, in: Proceedings of the Hydralab III joint transnational access user meeting, Hannover, 2010.

Personne, E., Perrier, A., and Tuzet, A.: Simulating water uptake in the root zone with a microscopic-scale model of root extraction, Agronomie, 23, 153-168, doi:10.1051/agro:2002081, 2003.

Perucca, E., Camporeale, C., and Ridolfi, L.: Significance of the riparian vegetation dynamics on meandering river morphodynamics, Water Resour. Res., 43, W03430, doi:10.1029/2006WR005234, 2007.

Plant, R.: A continuum model for root-growth, J. Theor. Biol., 98, 45-59, 1982.

Poggi, D. and Katul, G. G.: An experimental investigation of the mean momentum budget inside dense canopies on narrow gentle hilly terrain, Agr. Forest Meteorol., 144, 1-13, doi:10.1016/j.agrformet.2007.01.009, 2007.

Poggi, D., Katul, G. G., and Albertson, J. D.: Momentum Transfer and Turbulent Kinetic Energy Budgets within a Dense Model Canopy, Bound.-Lay. Meteorol., 111, 589-614, doi:10.1023/B:BOUN.0000016502.52590.af, 2004a.

Poggi, D., Porporato, A., Ridolfi, L., Albertson, J. D., and Katul, G. G.: The Effect of Vegetation Density on Canopy Sub-Layer Turbulence, Bound.-Lay. Meteorol., 111, 565-587, doi:10.1023/B:BOUN.0000016576.05621.73, 2004b.

Poggi, D., Katul, G., Albertson, J., and Ridolfi, L.: An experimental investigation of turbulent flows over a hilly surface, Phys. Fluids, 19, 036601, doi:10.1063/1.2565528, 2007.

Pollen, N.: Temporal and spatial variability in root reinforcement of streambanks: Accounting for soil shear strength and moisture, Catena, 69, 197-205, doi:10.1016/j.catena.2006.05.004, 2007.

Pollen, N. and Simon, A.: Estimating the mechanical effects of riparian vegetation on stream bank stability using a fiber bundle model, Water Resour. Res., 41, 1-11, doi:10.1029/2004WR003801, 2005.

Pollen-Bankhead, N. and Simon, A.: Hydrologic and hydraulic effects of riparian root networks on streambank stability: Is mechanical root-reinforcment the whole story?, Geomorphology, $116,353-362,2010$.
Portenfield, D.: Environmental sensing and directional growth of plant roots, in: Plant roots: the hidden half, Marcel Dekker, 2002.

Prosser, I. P., Dietrich, W. E., and Stevenson, J.: Flow Resistance and Sediment Transport by Concentrated Overland Flow in a Grassland Valley, Geomorphology, 13, 71-86, 1995.

Robinson, D.: Optimal relations between root length and nutrient inflow rate in plant root systems, J. Theor. Biol., 135, 359-370, doi:10.1016/S0022-5193(88)80250-9, 1988.

Rodriguez-Iturbe, I. and Rinaldo, A.: Fractal River Basins, Chance and Self-Organization, Cambridge University Press, Cambridge, 1997.

Roose, T. and Fowler, A.: A model for water uptake by plant roots, J. Theor. Biol., 228, 155-171, doi:10.1016/j.jtbi.2003.12.012, 2004.

Sakai, K.: Nonlinear dynamics and chaos in agricultural systems, Elsevier Science, Amsterdam, The Netherlands, 2001.

Sakals, M. and Sidle, R.: A spatial and temporal model of root cohesion in forest soils, Can. J. Forest Res., 34, 950-958, 2004.

Salas, E., Ozier-Lafontaine, H., and Nygren, P.: A fractal root model applied for estimating the root biomass and architecture in two tropical legume tree species, Ann. Forest Sci., 61, 337345, doi:10.1051/forest:2004027, 2004.

Schenk, H. J. and Jackson, R. B.: Rooting depths, lateral root spreads and below-ground/above-ground allometries of plants in water-limited ecosystems, J. Ecol., 90, 480-494, 2002a.

Schenk, H. J. and Jackson, R. B.: The global biogeography of roots, Ecol. Monogr., 72, 311-328, doi:10.1890/00129615(2002)072[0311:TGBOR]2.0.CO;2, 2002b.

Schenk, J. H.: Vertical Vegetation Structure Below Ground: Scaling from Root to Globe, Prog. Bot., 66, 341-373, 2005.

Schimper, A. F. W.: Pflanzengeographie auf physiologischer Grundlage, WILEY-VCH Verlag, Jena, Germany, 1935.

Schnauder, I. and Moggridge, H.: Vegetation and hydraulicmorphological interactions at the individual plant, patch and channel scale, Aquat. Sci., 71, 318-330, 2009.

Seminara, G.: Fluvial Sedimentary Patterns, Ann. Rev. Fluid Mech., 42, 43-66, doi:10.1146/annurev-fluid-121108-145612, 2010.

Sperry, J., Stiller, V., and Hacke, U.: Soil water uptake and water transport through root systems, in: Plant roots: the hidden half, edited by: Waisel, Y., Eshel, A., and Kafkafi, U., Marcel Dekker, New York, USA, 663-681, 2002.

Steiger, J., Gurnell, A., and Goodson, J.: Quantifying and characterizing contemporary riparian sedimentation, River Res. Appl., 19, 335-352, 2003.

Stokes, A.: Biomechanics of tree roots anchorage, in: Plant roots: the hidden half, edited by: Waisel, Y., Eshel, A., and Kafkafi, U., Marcel Dekker, New York, USA, 269-286, 2002.

Stokes, A., Ball, J., Fitter, A. H., Brain, P., and Coutts, M. P.: An Experimental Investigation of the Resistance of Model Root Systems to Uprooting, Ann. Bot., 78, 415-421, doi:10.1006/anbo.1996.0137, 1996.

Suresh, S.: Fatigue of materials, Cambridge University Press, Cambridge, 1998.

Takayasu, H.: Fractals in the physical sciences, Manchester University Press, Manchester, 1990.

Tal, M. and Paola, C.: Dynamic singlethresd channels maintained by the interaction of flow and vegetation, Geology, 35, 347-350, 2007. 
Tal, M., Gran, K. B., Murray, A. B., Paola, C., and Hicks, M.: Riparian vegetation as a primary control on channel characteristics in multi-thread rivers, Water Sci. Appl., 8, 43-58, 2004.

Tanaka, N. and Yagisawa, J.: Effects of tree characteristics and substrate condition on critical breaking moment of trees due to heavy flooding, Landscape Ecol. Eng., 5, 59-70, 2009.

Tillmann, W., Reul, H., Herold, M., Bruss, K. H., and van Gilse, J.: In-vitro wall shear measurements at aortic valve prostheses, J. Biomech., 17, 263-279, 1984.

Tockner, K. and Stanford, J.: Riverine flood plains: present state and future trends, Environ. Conserv., 29, 308-330, 2002.

Tooth, S. and Nanson, G. C.: The role of vegetation in the formation of anabranching channels in an ephemeral river, Northern plains, arid central Australia, Hydrol. Process., 14, 3099-3117, 2000.

Tubino, M., Repetto, R., and Zoletti, G.: Free bars in rivers, J. Hydraul. Res., 37, 759-775, 1999.

Waisel, Y. and Eshel, A.: Functional diversity of various constituents of a single root system, in: Plant roots: the hidden half, edited by: Waisel, Y., Eshel, A., and Kafkafi, U., Marcel Dekker, New York, USA, 157-174, 2002.
Waisel, Y., Eshel, A., and Kafkafi, U.: Plant roots: the hidden half, Marcel Dekker, New York, USA, 2002.

Wilson, C. A. M. E., Stoesser, T., Bates, P., and Batemann Pinzen, A.: Open Channel Flow through Different Forms of Submerged Flexible Vegetation, J. Hydraul. Eng.-ASCE, 129, 847-853, doi:10.1061/(ASCE)0733-9429(2003)129:11(847), 2003.

Wolman, M. G. and Miller, J. P.: Magnitude and Frequency of Forces in Geomorphic Processes, J. Geol., 68, 54-74, doi:10.1086/626637, 1960.

Xavier, P., Wilson, C., Aberle, J., Rauch, H., Schoneboom, T., Lammeranner, W., and Huw, T.: Drag force of flexible submerged trees, in: Proceedings of the Hydralab III, Joint User Meeting, Hannover, 2010.

Xie, Y., An, S., Wu, B., and Wang, W.: Density-dependent root morphology and root distribution in the submerged plant Vallisneria natans, Environ. Exp. Bot., 57, 195-200, doi:10.1016/j.envexpbot.2005.06.001, 2006. 